\title{
$\nabla$
}

\section{Final diagnosis of 86 cases included in differential diagnosis of American tegumentary leishmaniasis in a Brazilian sample: a retrospective cross-sectional study*}

\author{
Fernanda Tirelli ${ }^{1}$ \\ Ana Maria Roselino ${ }^{1}$
}

Sebastian Vernal ${ }^{2}$

DOI: http://dx.doi.org/10.1590/abd1806-4841.20175794

\begin{abstract}
BACKGROUND: Cutaneous leishmaniasis is distributed worldwide, including Brazil. Its several clinical forms need to be distinguished from other dermatoses. Clinical similarities and lack of a gold standard diagnostic tool make leishmaniasis-like lesions a challenging diagnosis.

OвJECTIVES. To report the final diagnosis of patients primarily suspected of having American tegumentary leishmaniasis (ATL).

METHODS. A retrospective cross-sectional study was conducted on the basis of medical records of 437 patients with clinical suspicion of ATL, registered in electronic hospital system between 1980 and 2013. Demographic, clinical, and laboratory data were compiled. RESULTS. Analysis of 86 cases (19.7\%) registered as ATL in one of the hypothesis revealed a different final diagnosis; 55 (63.9\%) and 31 cases (36.1\%) had skin and mucosal lesions, respectively. In 58 cases (67.4\%), the requested PCR did not identify Leishmania sp. In 28 cases $(32.5 \%)$, biopsies established the diagnosis and confirmed tumors, mycobacteriosis, and subcutaneous or systemic mycosis. Overall, $27 \%$ of the cases had inflammatory etiology, mainly nasal nonspecific inflammatory processes; $27 \%$ had infectious etiology, especially paracoccidioidomycosis and leprosy; $20 \%$ had neoplastic etiology, mainly basal and squamous cell carcinoma; $15 \%$ had miscellaneous etiology, including neuropathic ulcer, traumatic ulcers, idiopathic ulcer; $11 \%$ missed the follow-up.

STUDY LimitATIONS: Some cases had no final diagnosis due to loss of follow-up.

CONCLUSION. ATL can be confused with several differential diagnoses, especially inflammatory and infectious granulomatous diseases as well as non-melanoma skin cancers. Clinicians working in tropical areas should be aware of the main differential diagnosis of leishmaniasis-like lesions.
\end{abstract}

Keywords: Diagnosis, differential; Leprosy; Leishmaniasis; Mycoses; Skin neoplasms; Paracoccidioidomycosis

\section{INTRODUCTION}

Leishmaniasis is a zoonotic disease caused by a protozoa belonging to the genus Leishmania. It is transmitted by the bite of sand flies of the genus Phlebotomus. The wide geographic distribution, high incidence, and potentially mutilating clinical manifestations of leishmaniasis make this condition a major health concern. ${ }^{1}$ Depending on the infecting species, leishmaniasis may encompass visceral and tegumentary clinical forms. The latter form includes localized and disseminated cutaneous and mucocutaneous forms. Cutaneous leishmaniasis is prevalent in more than 90 countries; 1.5 million new cases are estimated to emerge per year. ${ }^{2}$ Most of cutaneous leishmaniasis cases have been reported in Africa, Middle East, and Latin America, mainly in Brazil. ${ }^{1,2}$
According to the Brazilian Ministry of Health, between 1991 and 2010 a mean of 27,374 cases of American tegumentary leishmaniasis (ATL) were recorded per year in Brazil, corresponding to a prevalence of 16.4 cases per 100,000 inhabitants. ${ }^{3}$ Most cases occurred in the North and Northeast regions (39\% each), followed by the Midwest (12.6\%), Southeast (7.2\%), and South (2.2\%). ${ }^{3}$ In the 1990 's, the state of São Paulo, localized in Southeastern Brazil, had the highest reported number of ATL cases: 835 cases and a detection rate of 2.6 per 100,000 inhabitants. ${ }^{3-5}$

Differential diagnosis of ATL still represents a challenge for physicians. Diverse clinical presentations of ATL, as well as the list of confounding diseases, especially granulomatous conditions

\section{Received on 14.03.2016.}

Approved by the Advisory Board and accepted for publication on 29.07.2016.

* Study conducted at the University Hospital, Faculdade de Medicina de Ribeirão Preto da Universidade de São Paulo (FMRP-USP) - Ribeirão Preto (SP), Brazil. Financial support: The first author received a scholarship from CNPq (Conselho Nacional de Pesquisa), the second author has received a scholarship from CAPES (Coordenação de Aperfeiçoamento de Pessoal de Nível Superior). The manuscript was partially supported by FAEPA (Fundação de Amparo ao Ensino, Pesquisa e Assistência).

Conflict of interest: None.

Division of Dermatology, Department of Medical Clinics, Faculdade de Medicina de Ribeirão Preto da Universidade de São Paulo (FMRP-USP) - Ribeirão Preto (SP), Brazil.

2 Medical Clinics Pos graduated Area, Faculdade de Medicina de Ribeirão Preto da Universidade de São Paulo (FMRP-USP) - Ribeirão Preto (SP), Brazil.

(C)2017 by Anais Brasileiros de Dermatologia 
like paracoccidioidomycosis, sporothrycosis, chromomycosis, cutaneous tuberculosis, and skin cancers such as basal cell carcinoma (BCC) and squamous cell carcinoma (SCC) make ATL diagnosis difficult. ${ }^{6}$ Although diagnosis can sometimes rely only on clinical-epidemiological criteria, laboratory tests are crucial. However, the lack of a gold standard diagnostic tool prevents ATL confirmation. ${ }^{7}$ In this context, knowing about diseases that mimic leishmaniasis is an essential skill for clinicians and such knowledge can avoid unnecessary patient exposure to toxic drugs used to treat ATL.

Regarding epidemiological, clinical, and diagnostic peculiarities of such a variety of diseases, this study aims to (1) report the disposal of ATL diagnosis when the initial clinical hypothesis in primary investigation is ATL and (2) describe the differential diseases confirmed in the precise final diagnosis.

\section{METHODS}

Study design. Retrospective cross-sectional study developed according to the STROBE statements.

Ethics. The Ethics Committee of the University Hospital, Faculdade de Medicina de Ribeirão Preto da Universidade de São Paulo (FMRP-USP) approved this study (\#371.472/2013).

Setting and Participants. This study was based on the records of 437 patients treated at the aforementioned hospital between 1980 and 2013. These patients were suspected to have ATL, which was registered as the differential diagnostic hypothesis in the medical charts. The International Classification of Diseases (ICD-10) data entered in the hospital digital system aided ATL diagnosis. Patients with ATL hypothesis and final and confirmed ATL diagnosis (ICD-10 = B55) were excluded from this study. ATL diagnosis was confirmed by at least two of the following criteria: clinical-epidemiological diagnosis compatible with ATL; positive leishmanin skin test; histopathology of skin or mucosa sample indicative of ATL, including the presence of amastigotes or not; and/or PCR positive for the Leishmania Viannia subgenus. It is worth mentioning that the University Hospital, Faculdade de Medicina de Ribeirão Preto da Universidade de São Paulo (FMRP-USP) is a tertiary public center for the diagnosis and treatment of tegumentary leishmaniasis in the northeastern region of the state of São Paulo.

Variables. The database was compiled on an Excel spreadsheet (Microsoft Office, Microsoft $\left.{ }^{\circledR}, 2015\right)$, in which the variables studied during analysis of the medical charts (paper and electronic databases) were summarized and complemented with a review of the laboratorial results. The following data were analyzed: (A) Epidemiological data: age, gender, profession, place of residence, city and state where the clinical manifestations of the disease started (whether urban or rural area, in the event of leisure and/or work near rivers), poultry farming, sun exposure, trauma with thorns and twigs, and comorbidities; (B) Clinical data: lesion localization, affected mucosa region; and (C) Laboratorial data: PCR and biopsy.

Epidemiological risk factors for ATL and its main differential diagnoses were rigorously searched in all medical charts. In the absence of any data, the assessed variable was not considered. When data were available, the factor was included as referred or denied by the patients. The main epidemiological factors reported by the patients are described in the results section. It is important to emphasize that the main limitation of the study is to be retrospective, and the lack of information about epidemiological variables was observed in the evaluated medical charts.

Statistics. Data were summarized with the aid of frequency tables, summary statistics, and $P$-values. Parametric assumptions were assessed by the Normal plot. For continuous variables with non-normal distribution, the nonparametric Mann-Whitney $U$ test was used to compare groups. Categorical variables between the groups were contrasted by using the Chi-square $\left(\mathrm{x}^{2}\right)$ test, although the Fisher exact test was used when the data were sparse. Significance was set at $P$-value $<0.05$; two-tails comparison was used. All the reported $P$-values were rounded to three decimal places. Statistical analyses were performed by means of the SPSS version 22.00 (SPSS v22, IBM ${ }^{\circledast}$, USA).

\section{RESULTS}

A total of 86 cases $(19.7 \%)$ with initial clinical hypothesis of ATL, registered in the University Hospital digital records, revealed a different final diagnosis. According to the clinical data, 55 (63.9\%) and 31 cases $(36.1 \%)$ had skin and mucosal lesions, respectively. Table 1 summarizes the demographic data.

At the onset of the clinical manifestations, the analyzed patients lived in Southeast region of Brazil, mainly in the state of São Paulo (particularly in the northeastern region of this state); only three patients were from the state of Minas Gerais. Patients stated

TABLE 1: Demographic data of the patients who presented

with cutaneous or mucous lesions and received differential diagnosis of ATL (86 patients)

\begin{tabular}{|c|c|c|c|}
\hline & $\begin{array}{l}\text { Cutaneous } \\
\quad(n=55)\end{array}$ & $\begin{array}{c}\text { Mucous } \\
(\mathrm{n}=31)\end{array}$ & P-value \\
\hline & \multicolumn{2}{|c|}{$\begin{array}{c}\text { Mean (Minimum / } \\
\text { Maximum) }\end{array}$} & \\
\hline Age (years) & $57(10 / 90)$ & $54(15 / 78)$ & 0.392 \\
\hline \multirow[t]{2}{*}{ Evolution time (years) } & $1(0.16 / 40)$ & $2(0.25 / 30)$ & 0.018 \\
\hline & N (\%) & N (\%) & \\
\hline \multicolumn{4}{|l|}{ Gender } \\
\hline Female & $20(36.3)$ & $18(58.0)$ & 0.071 \\
\hline Male & $35(63.6)$ & $13(41.9)$ & \\
\hline \multicolumn{4}{|l|}{ Place of onset } \\
\hline State of São Paulo & $53(96.3)$ & $30(96.7)$ & 1.000 \\
\hline State of Minas Gerais & $2(3.6)$ & $1(3.2)$ & \\
\hline \multicolumn{4}{|l|}{ Type of Housing } \\
\hline Rural & $26(47.2)$ & $9(29)$ & 0.114 \\
\hline Urban & $29(52.7)$ & $22(70.9)$ & \\
\hline \multicolumn{4}{|l|}{ Contact with rivers } \\
\hline Yes & $25(45.4)$ & $10(32.2)$ & 0.261 \\
\hline No & $30(54.5)$ & $21(67.7)$ & \\
\hline \multicolumn{4}{|l|}{ Occupation } \\
\hline Peasant & $17(30.9)$ & $3(9.6)$ & 0.033 \\
\hline Other & $38(69)$ & $28(90.3)$ & \\
\hline
\end{tabular}


that they lived mainly in urban areas (59.3\%). Thirty-five patients reported contact with rivers, including work and/or leisure activities, especially fishing activities. Main occupation among them was peasant $(n=20,23.3 \%)$, followed by 14 housewives $(16.2 \%)$ and 12 retired $(13.9 \%)$ individuals. No other occupation was reported with higher frequency. Peasants presented with cutaneous lesions more frequently as compared with mucosal lesions $(P$-value $=0.033)$.

Two patients reported trauma with thorns and/or twigs prior to the onset of lesions. Final diagnoses of these patients were cutaneous lesions with nasal mucosa commitment by paracoccidioidomycosis, and chromomycosis, respectively (Figure 1).

Poultry farming was identified in two patients, and this activity was related with one case of cutaneous cryptococcosis. The other patient discontinued the medical follow-up, so it was not possible to clarify the etiology of the ulcerated lesion.

Three patients had medical record of treated leprosy. Two of them were confirmed for ulcerated erythema nodosum of leprosy (Figure 1). The other patient had unspecific oral inflammatory process probably related to a mucosal reaction against acrylic-resin dental prosthesis. Another patient reported contact with a leprosy relative, but the final diagnosis was paracoccidioidomycosis (Figure 1). Only one patient declared previous diagnosis of tuberculosis, but her cutaneous ulcer was finally cataloged as traumatic.

A total of 27 patients informed chronic sun exposure. Among them, 21 had cutaneous lesion (19 were men; 13 were peasants). Final diagnosis of nine of them was non-melanoma skin cancer, mainly SCC (Figure 1).

Immunosuppression factors were identified in 11 patients. Two were under chronic corticosteroid therapy, one presented invasive aspergillosis, and one had diagnosis of nasal nonspecific inflammatory process, probably related to sinus hypertrophy and chronic sinusitis. An HIV patient and a lymphocytic chronic leukemia patient presented with cutaneous and mucosal ulcer, respectively. It was not possible to confirm the lesion etiology for neither of these two patients, and there was no specific treatment document- ed for them. The other seven patients had diabetes mellitus type 2 , but only one presented with neuropathic ulcer. In three of these patients, the lesion was associated with an infectious agent (sporothrycosis, paracoccidioidomycosis, and furunculosis).

Skin lesions were localized mostly on the limbs $(n=32$, $58.1 \%$ ) and face ( $\mathrm{n}=21,38.1 \%$ ), and less commonly on the trunk and scalp. Regarding the number of lesions, 36 cases (65.4\%) had an isolated lesion (Table 2). Among the mucosal lesions, the main affected area was the nasal mucosa $(n=27,87.1 \%)$; the other patients had oral mucosa involvement that included the hard palate or lip mucosa (Behçet disease, Figure 1).

Histopathological examination defined 28 cases (32.5\%) (Table 3), diagnosed mainly with tumors, mycobacteriosis, and subcutaneous and systemic mycosis. Specific diagnostic tools confirmed diagnosis of the other 58 patients (Figure 2). Diagnoses were classified into infectious, inflammatory, neoplastic, miscellaneous, and unclear (due to missed follow-up). Nasal nonspecific inflammatory process encompassed septal perforations due to unspecified cause, trauma, post-surgical outcome, and drug abuse (cocaine consumption, Figure 1), among others. "Miscellaneous" included skin ulcers

TABLE 2: Clinical data of the patients regarding lesion description for differential diagnosis of ATL (86 patients)

\begin{tabular}{lccc} 
& Number of Lesions & \multicolumn{2}{c}{$\begin{array}{c}\text { Location } \\
\mathbf{n}(\mathbf{\%})\end{array}$} \\
\hline $\begin{array}{l}\text { Cutaneous } \\
\text { Lesion } \\
(\mathrm{n}=55)\end{array}$ & Isolated Lesion 36(65.5) & Limbs & $32(58.1)$ \\
& More than one lesion 19(34.5) & Face & $21(38.1)$ \\
\hline $\begin{array}{l}\text { Mucous } \\
\text { Lesion } \\
(\mathrm{n}=31)\end{array}$ & Trunk & $5(9.0)$ \\
\hline
\end{tabular}
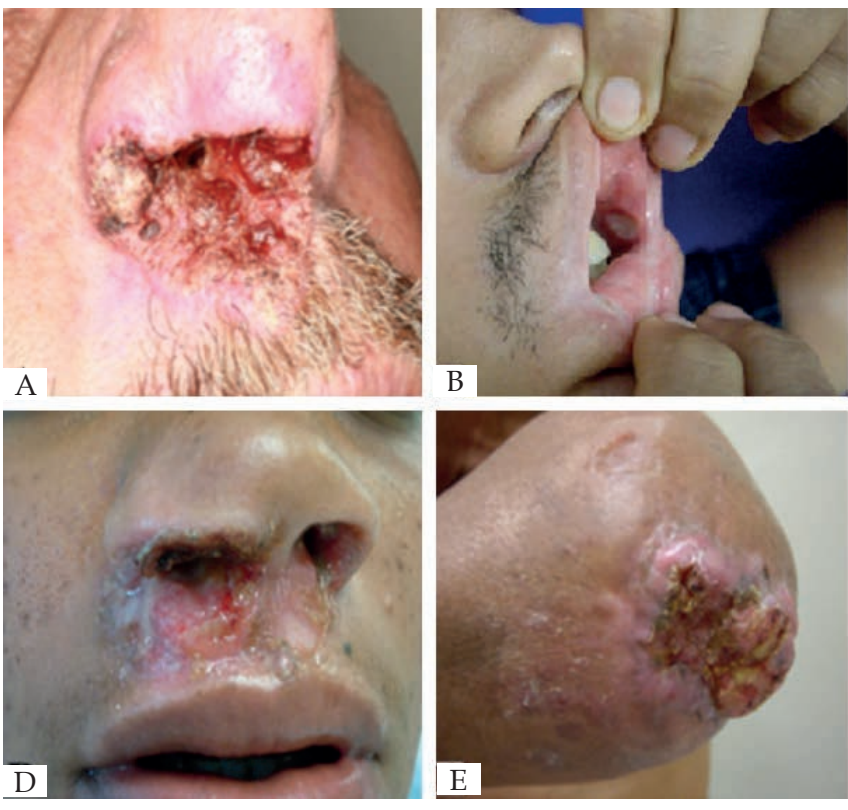
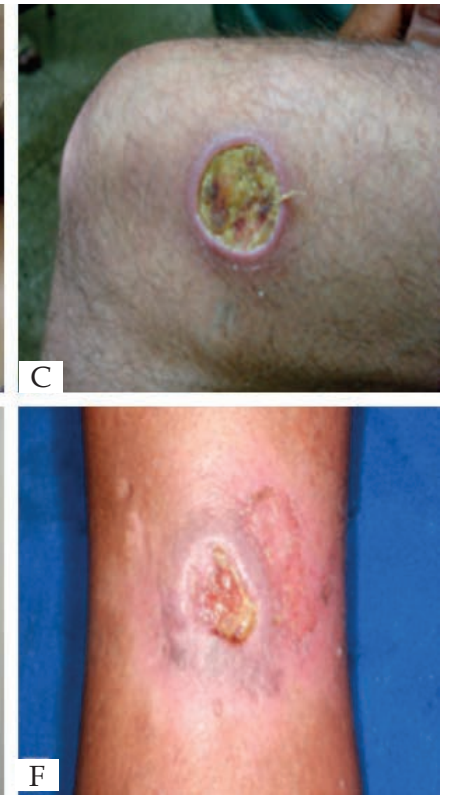

Figure 1:

A. Nasal mucous and perinasal ulcerated lesion: Paracoccidioidomycosis; B. Oral lesion: Behcet's disease; C. Well-defined ulcerated lesion in the knee: ulcerated (echtymatous) erythema nodosum leprosum; D. Nasal mucous and perinasal ulcerated lesion: Drug addiction (Cocaine user); E. Ulcerated lesion on the elbow: Squamous cell carcinoma; F. Well-defined ulcerated lesion in the: hypertensive ulcer 
TABLE 3: Histopathological findings in 28 cases of differential diagnosis of American tegumentary leishmaniasis

\begin{tabular}{|c|c|c|c|}
\hline Differential Diagnosis & $\mathbf{n}$ & $\%$ & Histopathological findings of ulcer biopsy \\
\hline Squamous cell carcinoma & 7 & 25.0 & $\begin{array}{l}\text { In general: Moderate and well differentiated squamous cell carcinoma. Most of them with } \\
\text { ulceration focus. Keratinized areas as well as cystic and fibrotic formations were frequently } \\
\text { found. }\end{array}$ \\
\hline Paracoccidioidomycosis & 6 & 21.4 & $\begin{array}{l}\text { In general: Most of them with mixed inflammatory infiltrate and granuloma formation. The } \\
\text { majority presented giant cells containing birefringent rounded structures displaying sporulation, } \\
\text { suggesting paracoccidioidomycosis. Silver staining (GMS) was performed as appropriate. }\end{array}$ \\
\hline Basal cell carcinoma & 5 & 17.8 & $\begin{array}{l}\text { In general: Moderate and well-differentiated solid basal cell carcinoma. Some biopsies revealed } \\
\text { chronic nonspecific inflammatory infiltrate and capillary ectasia. }\end{array}$ \\
\hline Leprosy & 4 & 14.2 & In general: Presence of acid fast bacillus in histiocytes cytoplasm or forming globi. \\
\hline Cutaneous tuberculosis & 1 & 3.5 & Granulomatous dermatitis with lobular panniculitis and caseous necrosis. \\
\hline Aspergillosis & 1 & 3.5 & $\begin{array}{l}\text { Nasal mucosa fragment with invasive fungal rhinitis and ulcerated area, with hyphae } \\
\text { morphologically suggestive of Aspergillus } s p \text { (invasive aspergillosis). }\end{array}$ \\
\hline Cryptococcosis & 1 & 3.5 & $\begin{array}{l}\text { Skin with chronic nonspecific superficial and deep dermatitis associated with fungal infection } \\
\text { by Cryptococcus sp. }\end{array}$ \\
\hline Chromomycosis & 1 & 3.5 & $\begin{array}{l}\text { Mixed inflammatory infiltrate with the presence of numerous Langhans giant cells; oval } \\
\text { and brownish fungal structures are observed amid infiltrates, which is highly suggestive of } \\
\text { chromomycosis. }\end{array}$ \\
\hline Behcet's disease & 1 & 3.5 & $\begin{array}{l}\text { Ulcerated mucosa with lush mixed inflammatory infiltrate in the corium, vascular neoformation, } \\
\text { extravasation of red blood cells, and vascular ectasia. }\end{array}$ \\
\hline $\begin{array}{l}\text { Wegener's } \\
\text { granulomatosis }\end{array}$ & 1 & 3.5 & $\begin{array}{l}\text { Nasal mucosa fragments coated with stratified squamous epithelium displaying numerous } \\
\text { vascular structures of small caliber and whose wall was pervaded by neutrophils and eosinophils, } \\
\text { interspersed with edema and mixed infiltrate. Histology suggested necrotizing granulomatous } \\
\text { vasculitis. }\end{array}$ \\
\hline
\end{tabular}

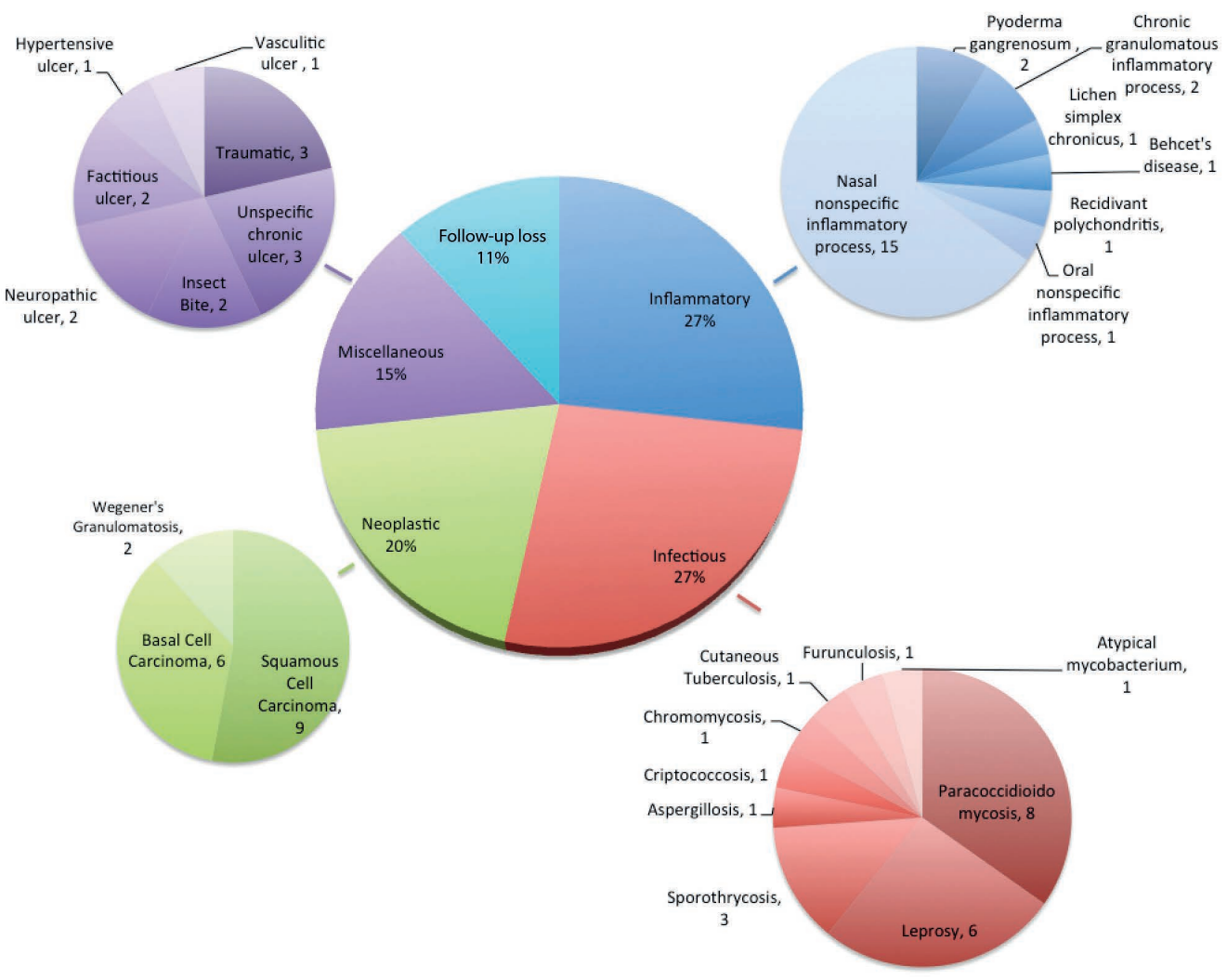

Figure 2:

Etiological classification of the final diagnosis of 86 cases for which American tegumentary leishmaniasis diagnosis was discarded 
secondary to diabetes mellitus type 2, hypertensive (Figure 1) and venous ulcers, as well as traumatic ulcer, ulcer due to insect bite, and unspecific chronic ulcer.

Skin biopsy samples were collected from 58 patients to perform PCR for Leishmania sp. identification. All the samples tested negative (Table 4).

\section{DISCUSSION}

ATL diagnosis is still a difficult task for physicians, even for dermatologist specialists - there is no gold standard diagnostic tool, and investment in research in neglected diseases is scarce ${ }^{7}$. Diagnosis of mucocutaneous leishmaniasis challenges physicians to an even larger extent because the immune response in the affected area is high, not to mention that invasive techniques are necessary to diagnose the cases of nasopharyngeal deep lesions. 8,9 The long list of confounding diseases of ATL, including the diverse range of etiologies described in this study, makes ATL diagnosis even more complex. The drugs that are currently available for ATL treatment are highly toxic, so the final diagnosis is crucial for healthcare practitioners dealing with skin and mucosal leishmaniasis-like clinical lesions. ${ }^{10}$

TABLE 4: Final diagnosis of 58 cases that presented

ulcerated or mucous lesion with documented negative PCR for Leishmania sp. identification

\begin{tabular}{|c|c|c|c|c|}
\hline \multirow[t]{2}{*}{ Final diagnosis } & \multicolumn{2}{|c|}{ Cutaneous } & \multicolumn{2}{|c|}{ Mucous } \\
\hline & $\mathbf{n}$ & $\%$ & $\mathbf{n}$ & $\%$ \\
\hline $\begin{array}{l}\text { Nasal nonspecific inflammatory } \\
\text { process }\end{array}$ & & 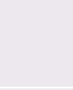 & 13 & 22.4 \\
\hline Loss of follow-up & 5 & 8.6 & & - \\
\hline Basal cell carcinoma & 4 & 6.8 & 1 & 1.7 \\
\hline Squamous cell carcinoma & 4 & 6.8 & 1 & 1.7 \\
\hline Paracoccidioidomycosis & 2 & 3.5 & 3 & 5.2 \\
\hline Unspecific chronic ulcer & 4 & 6.8 & & - \\
\hline Leprosy & 2 & 3.5 & 2 & 3.5 \\
\hline Traumatic & 1 & 1.7 & 1 & 1.7 \\
\hline Neuropathic ulcer & 2 & 3.5 & & - \\
\hline Wegener's granulomatosis & & 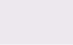 & 2 & 3.5 \\
\hline Cryptococcosis & 1 & 1.7 & & - \\
\hline Chromomycosis & 1 & 1.7 & & - \\
\hline Sporothrycosis & 1 & 1.7 & & - \\
\hline Cutaneous tuberculosis & 1 & 1.7 & & - \\
\hline Pyoderma gangrenosum & 1 & 1.7 & & - \\
\hline Insect bite & 1 & 1.7 & & - \\
\hline Hypertensive ulcer & 1 & 1.7 & & - \\
\hline Vasculitic ulcer & 1 & 1.7 & & - \\
\hline Lichen simplex chronicus & 1 & 1.7 & & - \\
\hline $\begin{array}{l}\text { Oral nonspecific inflammatory } \\
\text { process }\end{array}$ & & & 1 & 1.7 \\
\hline Invasive aspergillosis & & & 1 & 1.7 \\
\hline
\end{tabular}

Faced with a suspected case of cutaneous leishmaniasis, we should pay attention to some details in the interview: time of clinical evolution of the lesion, lesion characteristics, history of exposure to areas close to rivers, previous skin lesion (in case of mucous form), profession, and recent travel history and sandfly bites. ${ }^{6,7}$

As for the physical examination, it is important to research the following: number (ATL can be single or multiple), and characteristics of the lesions (ATL cutaneous lesion is a painless ulceration with indurated border), location (ATL usually affects the lower limbs; skin cancer usually affect the face and upper limbs). ${ }^{6,7}$ Moreover, pulmonary findings may be an associated link with chronic paracoccidioidomycosis.

Regarding the topography of the lesions, facial and scalp lesions make differential diagnosis with mainly carcinomas (sun-exposure areas); oral and nasal lesions may be associated with paracoccidioidomycosis and leishmaniasis; ${ }^{6,7}$ genital lesions are related to sexually transmitted diseases, such as chancre and cancroid.

In general, parasitic diseases affect men more frequently and more severely than women, and ATL is no exception. ${ }^{11-13}$ External factors like outdoor activities or work exposure to infectious/ risk factor sources during activities conducted outdoors could bias this fact. Indeed, the number of men in frequent contact with rivers and involved in outdoor duties, such as the tasks carried out by peasants or masons, is greater than the number of women in these same situations (women tend to perform indoor activities; e.g. housewife duties). Interestingly, this sex-related difference in ATL is not apparent in patients' aged 0-14 years. Instead, infection develops by adolescence (age $>15$ years) and continues in aging patients. ${ }^{14}$ As for paracoccidioidomycosis infection, epidemiological Brazilian data have pointed out that male patients are at higher risk of acquiring this disease too. ${ }^{15}$ Chromomycosis infection has this same epidemiological profile in Brazil, especially among farmers aged 50-60 years, and the state of São Paulo follows this same trend. ${ }^{16,17}$ Regarding leprosy, a descriptive study conducted in the state of São Paulo revealed that this disease predominates in men. ${ }^{18}$ Lastly, considering the main differential diagnosis of neoplastic etiology, a case-control study performed in the South region of Brazil showed that BCC diagnosis prevails among women ( $\mathrm{n}=74,58.2 \%)$. ${ }^{19}$ However, other studies involving larger series around the world revealed higher prevalence of BCC in men. ${ }^{20-22}$ SCC is also more prevalent in men. ${ }^{21}$

The same sex-related bias could be true in terms of age. External factors could underlie the high prevalence of skin lesion in patients in working age (30-50 years) described in this study, especially in the case of differential diagnosis of infectious etiology. Notwithstanding, age is a well-known risk factor for neoplastic etiology, and the incidence of skin cancers BCC and SCC dramatically increases among aging patients. ${ }^{20,21}$

The University Hospital, Faculdade de Medicina de Ribeirão Preto da Universidade de São Paulo (FMRP-USP) is the reference regional center for diagnosis and treatment of ATL cases. Most patients assisted at this institution come from the northeastern region of the state of São Paulo or from the southern region of the state of Minas Gerais, thereby involving a considerable part of the Southeastern Brazilian population. In this report, the onset of clini- 
cal manifestations occurred while the majority of the patients were living in the state of São Paulo, previously described as an endemic area for ATL. ${ }^{4,5}$ Health practitioners working in this region should be aware of at least the main clinical differential diagnoses of ATL that could emerge in the area. Knowledge about and correct use of clinical diagnostic tools as well as proper selection of subsidiary laboratorial exams to determine the final etiology of the skin lesion should be mandatory among clinicians.

Occupation of almost a quarter of the patients surveyed here was related to farming $(23.2 \%)$. Farming activities expose the individual to a range of factors that include bites by the Leishmania-vector sand flies, trauma with contaminated organic material (especially thorns and/or twigs), soil, domestic animals, and chronic sun exposure, among others. ${ }^{23-27}$ In our series, $31.4 \%$ of the patients were chronically exposed to sun; nine of them were diagnosed with BCC or SCC. Of the two patients who reported trauma with thorns and/or twigs, one had diagnosis of chromomycosis. Despite confirmation of the diagnosis by histopathological examination due to initial clinical suspicion of ATL, when chromomycosis is the first hypothesis, other cheap and easy supplementary tests like direct mycological examination and/or culture are available. ${ }^{24}$ Poultry farming was uncommon in our group of patients - there were only two descriptions in all of the analyzed medical charts. One of the patients was diagnosed with cutaneous cryptococcosis. Like chromomycosis, cryptococcosis could also be diagnosed by direct mycological examination or culture. ${ }^{26}$

The fact that skin lesion predominated on the limbs (58.1\%) was probably due to exposure of these parts of the body, especially the lower limbs, to traumatic factors. The upper limbs are an easy target for sand fly bites and are more prone to traumatic lesion and chronic sun exposure. The facial region was also frequently affected (38.1\%), and chronic sun exposure should be identified upon clinical examination of skin lesions. ${ }^{27}$ Location, evolution time, smoking habit, radiation or arsenic exposure, familiar background, and other risk factors should be investigated to complement the medical history of patients with facial skin lesions.

Skin lesions were more frequent than mucosal lesions in our patients (55 versus 31 cases). Normally, mucocutaneous leishmaniasis occurs in 3\% of the patients with a history of cutaneous leishmaniasis and typically appears months or years after the initial skin infection. ${ }^{1}$ Here, we discuss the two main differential diagnosis of infectious etiology in mucosal lesion. Paracoccidioidomycosis infection could involve oral, pharyngeal, and laryngeal mucosal tissues in up to $70 \%$ of adult patients. Classical clinical presentation is a superficial ulcer with granular appearance and hemorrhagic points (mulberry-like stomatitis). The face is a common site of lesions, particularly around the mouth and nose, with progression to the nasal vestibule and floor of the nose. ${ }^{25}$ Pulmonary involvement should always be evaluated. As for leprosy, mucosal lesions can emerge in patients with the multibacillary clinical form of the disease. ${ }^{28}$

Among the 10 differential diagnoses confirmed by histopathological examination, three of them required biopsy: SCC, BCC, and Wegener's disease. ${ }^{29-31}$ As mentioned above, the other diagnoses demanded supplementary laboratorial tests before biopsy. PCR was not mandatory in any of the discarded diagnoses presented in Table 4, although this technique has proven to be a good diagnostic tool for ATL diagnosis because it is highly sensitive and specific, especially for mucocutaneous lesions. ${ }^{7,32,33}$ Negative PCR results helped to dismiss Leishmania infection in 13 cases of nasal mucosal inflammatory process and in nine cases of skin lesions of miscellaneous etiologies.

In relation to laboratorial methods, it is worth mentioning the main complementary exams necessary to reach the final diagnosis for skin or mucosal lesions: histopathology; direct and culture examination for fungus and leishmania; PCR for leishmania, Mycobacterium spp., M. leprae, M. tuberculosis identification; intradermal tests such as PPD, Montenegro, Mitsuda; serologic tests for leishmaniasis, fungus and syphilis (VDRL, FTA-ABS) 7, 13-15,18,25,28,32,33 When appropriated, other diseases, such as cutaneous lupus erythematosus and sarcoidosis need to be investigated.

In spite of all the recent medical advances, this study has revealed limitations during ATL diagnosis. For example, in the case of inflammatory etiology, 15 patients had a final diagnosis of "nasal nonspecific inflammatory process". Although our hospital offers tertiary care and even though the main diagnostic tools are available in our institution, it was not possible to reach precise etiology. In this situation, epidemiological and clinical data, including complete anamnesis and risk factor assessment, are indispensable. Another hard task for physicians is to avoid loss of patients' follow-up. Eleven percent of our cases were not diagnosed due to lack of adherence. These patients missed not only etiology confirmation, but also treatment evaluation and tracking. As a result, they were considered eventual communicants in infectious diseases and/or environmental risk factor detection, which could harm other individuals.

It is worth highlighting that although the majority of these patients are not at risk of dying, many of them could have mutilating outcomes that might culminate in complications and social issues like stigmatization, functional disability, and prejudice at work. Confirming the diagnosis is essential to prevent such undesirable consequences and to establish the most appropriate therapeutic approach for each patient.

\section{CONCLUSION}

ATL could be confused with many differential diagnoses. Granulomatous diseases, especially paracoccidioidomycosis and leprosy, were the main differential diagnosis of infectious etiology in our 86 reported cases. BCC and SCC came up as the main distractor during clinical ATL diagnosis, especially when they were located in the facial region. $\square$

\section{ACKNOWLEDGEMENTS}

The authors thank Sandra Medeiros and Natalia de Paula for technical assistance with routine PCR assays, and Dr. Ciro Martins Gomes, PhD, for reviewing the manuscript. 


\section{REFERENCES}

1. World Health Organization. Control of the leishmaniasis: report of a meeting of the WHO Expert Committee on the Control of Leishmaniases, Geneva, 22-26 March 2010 xii-xiii, 1-186, back cover.

2. Kevric I, Cappel MA, Keeling JH. New World and Old World Leishmania Infections: A Practical Review. Dermatol Clin. 2015:33:579-93.

3. Brasil. Ministério da Saúde. Secretaria de Vigilância em Saúde. Departamento de Vigilância Epidemiológica. Manual de Vigilância da Leishmaniose Tegumentar Americana. 2. ed. Brasília : Editora do Ministério da Saúde; 2007. 182 p. - (Série A. Normas e Manuais Técnicos). [acesso 2 Mar 2016]. Disponível em: http:// bvsms.saude.gov.br/bvs/publicacoes/manual_vigilancia_leishmaniose_2ed. pdf2007.

4. Governo do Estado de São Paulo. Secretaria de Saúde. SUCEN - Superintendência de Controle de Endemias. Leishmaniose Tegumentar Americana. Situação Atual, 2008. [acesso 2 Mar 2016]. Disponível em://www.saude.sp.gov.br/ sucen-superintendencia-de-controle-de-endemias/programas/leishmaniosetegumentar-americana/situacao-atual:2008.

5. Shimabukuro PH, da Silva TR, Ribeiro FO, Baton LA, Galati EA. Geographica distribution of American cutaneous leishmaniasis and its phlebotomine vectors (Diptera: Psychodidae) in the state of São Paulo, Brazil. Parasit Vectors. 2010 Dec 20:3:121.

6. Bailey MS, Lockwood DN. Cutaneous leishmaniasis. Clin Dermatol. 2007;25:20311.

7. Gomes CM, Paula NA, Morais 00, Soares KA, Roselino AM, Sampaio RN. Complementary exams in the diagnosis of American tegumentary leishmaniasis An Bras Dermatol. 2014;89:701-9.

8. Maretti-Mira AC, de Pinho Rodrigues KM, de Oliveira-Neto MP, Pirmez C, Craft N MMP-9 activity is induced by Leishmania braziliensis infection and correlates with mucosal leishmaniasis. Acta Trop. 2011;119:160-4.

9. Weinkopff T, Mariotto A, Simon G, Hauyon-La Torre $Y$, Auderset F, Schuster S, et al. Role of Toll-like receptor 9 signaling in experimental Leishmania braziliensis infection. Infect Immun. 2013;81:1575-84.

10. Wise ES, Armstrong MS, Watson J, Lockwood DN. Monitoring toxicity associated with parenteral sodium stibogluconate in the day-case management of returned travellers with New World cutaneous leishmaniasis (corrected). PLoS Negl Trop Dis. 2012;6:e1688.

11. Klein SL. Hormonal and immunological mechanisms mediating sex differences in parasite infection. Parasite Immunol. 2004;26:247-64.

12. Roberts $\mathrm{CW}$, Walker W, Alexander J. Sex-associated hormones and immunity to protozoan parasites. Clin Microbiol Rev. 2001;14:476-88.

13. Moore EM, Lockwood DN. Leishmaniasis. Clin Med (Lond). 2011;11:492-7.

14. Murback ND, Hans Filho G, Nascimento RA, Nakazato KR, Dorval ME. American cutaneous leishmaniasis: clinical, epidemiological and laboratory studies conducted at a university teaching hospital in Campo Grande, Mato Grosso do Sul, Brazil. An Bras Dermatol. 2011;86:55-63.

15. Blotta MH, Mamoni RL, Oliveira SJ, Nouér SA, Papaiordanou PM, Goveia A, et al. Endemic regions of paracoccidioidomycosis in Brazil: a clinical and epidemiologic study of 584 cases in the southeast region. Am J Trop Med Hyg. 1999:61:390-4.

16. Minotto R, Bernardi CD, Mallmann LF, Edelweiss MI, Scroferneker ML. Chromoblastomycosis: a review of 100 cases in the state of Rio Grande do Sul, Brazil. J Am Acad Dermatol. 2001;44:585-92.

17. Marques GF, Masuda PY, Sousa JM, Barreto JA, Wachholz PA. Clinical and demographic profile of chromoblastomycosis in a referral service in the midwest of São Paulo state (Brazil). An Bras Dermatol. 2015;90:140-2

18. Porto AC, Figueira RB, Barreto JA, Lauris JR. Evaluation of the social, clinical and laboratorial profile of patients diagnosed with leprosy in a reference center in São Paulo. An Bras Dermatol. 2015 Mar-Apr:90:169-77.

19. Gon A, Minelli L. Risk factors for basal cell carcinoma in a southern Brazilian population: a case-control study. Int J Dermatol. 2011;50:1286-90.

20. Hannuksela-Svahn A, Pukkala E, Karvonen J. Basal cell skin carcinoma and other nonmelanoma skin cancers in Finland from 1956 through 1995. Arch Dermatol. 1999;135:781-6

21. Green A, Battistutta D, Hart V, Leslie D, Weedon D. Skin cancer in a subtropical Australian population: incidence and lack of association with occupation. The Nambour Study Group. Am J Epidemiol. 1996;144:1034-40.

22. Chuang TY, Popescu A, Su WP, Chute CG. Basal cell carcinoma. A population-based incidence study in Rochester, Minnesota. J Am Acad Dermatol. 1990;22:413-7.

23. Ramos-e-Silva M, Vasconcelos C, Carneiro S, Cestari T. Sporotrichosis. Clin Dermatol. 2007;25:181-7.
24. Krzyściak PM, Pindycka-Piaszczyńska M, Piaszczyński M. Chromoblastomycosis. Postepy Dermatol Alergol. 2014:31:310-21.

25. Marques SA. Paracoccidioidomycosis. Clin Dermatol. 2012;30:610-5.

26. Negroni R. Cryptococcosis. Clin Dermatol. 2012;30:599-609.

27. Schmitt J, Seidler A, Diepgen TL, Bauer A. Occupational ultraviolet light exposure increases the risk for the development of cutaneous squamous cell carcinoma: a systematic review and meta-analysis. Br J Dermatol. 2011;164:291-307.

28. Morgado de Abreu MA, Roselino AM, Enokihara M, Nonogaki S, Prestes-Carneiro LE, Weckx LL, et al. Mycobacterium leprae is identified in the oral mucosa from paucibacillary and multibacillary leprosy patients. Clin Microbiol Infect. 2014:20:59-64

29. Alam M, Ratner D. Cutaneous squamous-cell carcinoma. N Engl J Med. 2001:344:975-83.

30. Rubin Al, Chen EH, Ratner D. Basal-cell carcinoma. N Engl J Med. 2005;353:2262-9.

31. Daoud MS, Gibson LE, DeRemee RA, Specks U, el-Azhary RA, Su WP. Cutaneous Wegener's granulomatosis: clinical, histopathologic, and immunopathologic features of thirty patients. J Am Acad Dermatol. 1994;31:605-12.

32. Gomes CM, Mazin SC, Santos ER, Cesetti MV, Bächtold GA, Cordeiro JH, et al. Accuracy of mucocutaneous leishmaniasis diagnosis using polymerase chain reaction: systematic literature review and meta-analysis. Mem Inst Oswaldo Cruz. 2015:110:157-65

33. Motta AC, Lopes MA, Ito FA, Carlos-Bregni R, de Almeida OP, Roselino AM. Oral leishmaniasis: a clinicopathological study of 11 cases. Oral Dis. 2007:13:335-40.

\author{
MAILING ADDRESS: \\ Fernanda Tirelli \\ Avenida Bandeirantes, 3900 \\ 14049-900 - Ribeirão Preto, SP \\ Brazil \\ E-mail:fernanda.tirelli.rocha@usp.br
}

How to cite this article: Tirelli F, Vernal S, Roselino AM. Final diagnosis of 86 cases included in differential diagnosis of American tegumentary leishmaniasis in a Brazilian sample: a retrospective cross-sectional study. An Bras Dermatol. 2017;92(5):642-8. 